\title{
Эффективность педагогического сопровождения познавательной деятельности студентов Вуза
}

\author{
Кучумов Д.В. *, Ямалетдинова Г.А. \\ Гуманитарный университет \\ 2. Екатеринбург, Россия \\ ORCID: oooo-0oo2-4697-4228, yamalga@mail.ru \\ ORCID: oooo-ooo2-7936-9235,ku.dm2015@yandex.ru*
}

\begin{abstract}
Аннотация: Способность активно обучаться на протяжении всей жизни является необходимой компетенцией специалиста, и это стало важной задачей института высшего образования в современном мире. В данной работе рассмотрена эффективность применениямодели педагогического сопровождения познавательной деятельности студентов на занятиях восточным единоборством при помощи анализа статистических данных полученных в результате эксперимента. Материалъ и методъ. Анализ и обобщение научной литературы, тестирование показателей физического здоровья, методы математической статистики. Резулътатъ. Оценивая физическое состояние студенток рядом тестов до и после эксперимента, мы наблюдали статистически достоверные улучшения показателей контрольной и экспериментальной групп, но показатели экспериментальной группы стали выше, и более однородны. Темп прироста в экспериментальной группе составил диапазон от 19,06 \% до 68,37 \%, а в контрольной группе от 12,25 \% до 58,89 \%. Заключение. Проанализированы данные, подтвердившие, что применение модели педагогического сопровождения познавательной деятельности при преподавании восточных единоборств студентам нефизкультурного вуза оказало позитивное влияние на показатели состояния здоровья.
\end{abstract}

Ключевые слова: познавательная деятельность, восточные единоборства, тестирование, физическое здоровье, самоуправление, показатели.

Для цитирования: Кучумов Д.В.*, Ямалетдинова Г.А. Эффективность педагогического сопровождения познавательной деятельности студентов Вуза. Педагогкио-психологические и медико-биологические проблемы физической культуры и спорта. 2020; 15(4): .67-70 DOI: 10.14526/2070-4798-2020-15-4-67-70

\section{Effectiveness of Pedagogical support of Cognitive activity of University students}

\author{
Dmitrij V. Kuchumov*, Galina A. Yamaletdinova \\ Humanitarian University \\ Yekaterinburg, Russia \\ ORCID: oooo-0oo2-4697-4228, yamalga@mail.ru \\ ORCID: oooo-ooo2-7936-9235,ku.dm2015@yandex.ru*
}

\begin{abstract}
The ability to actively learn throughout life is a necessary competence of a specialist, and this has become an important task of the higher education institute in the modern world. In this paper, the effectiveness of students' cognitive activity pedagogical support model application in martial arts classes is considered using the analysis of statistical data obtained as a result of the experiment. Materials and methods. Analysis and generalization of scientific literature, testing of physical health indicators, methods of mathematical statistics. Results. Evaluating the physical condition of female students with a series of tests before and after the experiment, we observed statistically significant improvements in the indicators of the control and experimental groups, but the indicators of the experimental group became higher and more uniform. The growth rate in the experimental group ranged from $19.06 \%$ to $68.37 \%$, and in the control group from $12.25 \%$ to $58.89 \%$. Conclusion. We analyzed the data that confirmed the use of the cognitive activity pedagogical support model in teaching martial arts to students of non-physical
\end{abstract}


culture universities had a positive impact on health indicators.

Keywords: cognitive activity, martial arts, testing, physical health, self-management, indicators.

For citation: Dmitrij V. Kuchumov*, Galina A. Yamaletdinova. Effectiveness of Pedagogical support of Cognitive activity of University students. Russian Journal of Physical Education and Sport. 2020; 15(4): 67-70. DOI: 10.14526/2070-4798-2020-15-4-67-70

\section{ВВЕДЕНИЕ}

B

современной

ухудшение здоровья населения страны

в целом, и обучающейся молодежи в частности,подтверждено большим количеством исследований и практическим опытом педагогов по физическому воспитанию. Именно студенты являются «группой риска» по большому спектру паталогических состояний и заболеваний, многие из которых обусловлены как социальным положением, так и самой спецификой учебной деятельности. В то же время ФГОС нового поколения утверждает стратегической задачей сохранение и укрепление здоровья, формирование ценностного отношения к здоровому образу жизни на основе личностного и социального развития. Это отражено в рабочих программах дисциплин и элективных курсов, преподаваемых в учреждениях высшего образования [1,2,3,4].

Восточные единоборства содержат в себе потенциал развития личности по многим интересующим нас направлениям, как средство и метод воспитания, и как инструмент для сохранения и укрепления здоровья. В рамках элективного курса при обучении студентов в вузе, мы свободны от необходимости достижения высокого спортивного результата, характерной для спортивных школ. Это позволяет расширить и разнообразить учебный процесс, сделать его более вариативным и индивидуализированным, вывести на первый план воспитание личности в целом, а не развитие личностных особенностей, способствующих достижению высоких результатов на соревнованиях. Полагаем, что это положительно влияет на желаемый итоговый результат при обучении студентов восточным единоборствам.

\section{МАТЕРИАЛЫ И МЕТОДЫ}

Сравнительно-сопоставительный анализ психолого-педагогической литературы; изучение опыта работы тренеров по восточным единоборствам; педагогическое наблюдение; анкетный опрос тренеров; самодиагностика психофизического состояния; эксперимент (констатирующий и формирующий); стандартные методики математической статистики.

Анализ и обобщение литературных данных позволил выявить структурные компоненты модели педагогического сопровождения познавательной деятельности студентов на занятиях единоборствами $[6,7,8,9]$. Модель представляет собой целостность функционально взаимосвязанных элементов: цели и результата деятельности, принципов, структуры, организационно-педагогических условий, критериев и показателей, уровней сформированности, отражающих еe эффективность.

Для продуктивной реализации модели необходимо тесное взаимодействие принципов организации практической психологопедагогической деятельности преподавателя и студентов. К ним относятся принципы: гуманистический, системности и целостности, взаимодействия психических и физических сил человека, оздоровительный, индивидуализации, вариативности, контроля и самоконтроля, природосообразности, специальные принципы тренировки, управления и самоуправления.

\section{РЕЗУЛЬТАТЫ И ОБСУЖДЕНИЕ}

Исследование было выполнено в Автономной некоммерческой организации высшего образования «Гуманитарный университет» г. Екатеринбурга в период с 2016 по 2019 год.

опытно-экспериментальном исследовании приняли участие 99 студенток в возрасте от 18 до 24 лет. В экспериментальной группе (48 человек), тренировочные занятия проводились с учетом разработанной нами 
модели педагогического сопровождения познавательной деятельности. В контрольной группе (51 человек), тренировочные занятия осуществлялись по традиционной рабочей программе дисциплины «Физическая культура и спорт: Восточные единоборства». Занятия в экспериментальной группе имели направленность на поддержку собственной созидательной активности студента, его способности самостоятельно формулировать, ставить и решать учебно-тренировочные задачи. Натренировках создавалисьпредпосылкипоформированию установки к активной, осознанной и целенаправленной работе над собой. Со стороны педагога использовались следующие Таблица 1 методы воздействия: информационные, психологические, педагогические методы и приемы, формы организации обучения и взаимодействия.

Оценка состояния физического здоровья до и после эксперимента проводилась по методикам следующих авторов:

Определение биологического возраста (В.П.Войтенко), Комплексная оценка уровня здоровья (Г.А. Апанасенко), Оценка адаптационного потенциала (Р.М.Баевский), Оценка работоспособности сердца (проба Руфье).

Полученные результаты представлены в таблице 1.

\begin{tabular}{|c|c|c|c|c|c|c|c|}
\hline \multicolumn{8}{|c|}{ Физическое здоровье } \\
\hline \multirow{2}{*}{ № } & \multirow{2}{*}{ Показатели } & \multirow{2}{*}{ Группы } & \multirow{2}{*}{ Период } & \multicolumn{4}{|c|}{ Статические параметры } \\
\hline & & & & M & $\mathrm{M}+,-\mathrm{m}$ & $\mathrm{V}, \%$ & $\square \mathrm{M}, \%$ \\
\hline \multirow{4}{*}{1} & \multirow{4}{*}{$\begin{array}{c}\text { Биологический } \\
\text { возраст, лет }\end{array}$} & \multirow{2}{*}{$\ni$} & До & $\begin{array}{l}25,94 \\
22,5\end{array}$ & 3,29 & $12,71 \%$ & \\
\hline & & & После & $\begin{array}{c}21 \\
19.3\end{array}$ & 1,68 & $8,00 \%$ & $19,06 \%$ \\
\hline & & \multirow{2}{*}{ K } & До & 24,89 & 2,02 & $8,13 \%$ & \\
\hline & & & После & 21,84 & 1,53 & $7,04 \%$ & $12,26 \%$ \\
\hline \multirow{4}{*}{2} & \multirow{4}{*}{$\begin{array}{c}\text { Комплексная оценка } \\
\text { уровня здоровья, } \\
\text { уровень }\end{array}$} & \multirow{2}{*}{$\ni$} & До & 5,44 & 5,44 & $43,29 \%$ & \\
\hline & & & После & 9,16 & 3,55 & $38,75 \%$ & $68,37 \%$ \\
\hline & & \multirow{2}{*}{ K } & До & 4,73 & 2,40 & $50,67 \%$ & \\
\hline & & & После & 7,52 & 2,31 & $30,80 \%$ & $58,89 \%$ \\
\hline \multirow{4}{*}{3} & \multirow{4}{*}{$\begin{array}{l}\text { Адаптационный } \\
\text { потенциал, балл }\end{array}$} & \multirow{2}{*}{$\ni$} & До & 2,01 & 0,25 & $21,21 \%$ & \\
\hline & & & После & 1,73 & 0,36 & $12,55 \%$ & $13,97 \%$ \\
\hline & & \multirow{2}{*}{$\mathrm{K}$} & До & 2,30 & 0,35 & $15,24 \%$ & \\
\hline & & & После & 2,00 & 0,23 & $11,80 \%$ & $13,07 \%$ \\
\hline \multirow{4}{*}{4} & \multirow{4}{*}{ Тест Руфье, ус.ед } & \multirow{2}{*}{$\vartheta$} & До & 7,05 & 2,70 & $38,10 \%$ & \\
\hline & & & После & 5,86 & 2,23 & $19,33 \%$ & $16,78 \%$ \\
\hline & & \multirow{2}{*}{ K } & До & 7,89 & 1,84 & $39,47 \%$ & \\
\hline & & & После & 6,63 & 1,95 & $23,36 \%$ & $16,00 \%$ \\
\hline
\end{tabular}




\section{ЗАКЛЮЧЕНИЕ}

При оценке состояния студенток рядом тестов до и после эксперимента, мы наблюдали статистически достоверные улучшение показателей физического здоровья контрольной и экспериментальной групп, но показатели экспериментальной группы стали выше, и более однородны. Таким образом, мы можем обоснованно утверждать, что достигнуты результаты по выбранным показателям, следовательно, реализация модели педагогического сопровождения познавательной деятельности на занятиях по восточному единоборству положительно повлияла на состояние здоровья студенток.

\section{СПИСОК ЛИТЕРАТУРЫ}

1. Осетрина Д. А. Причины ухудшения состояния здоровья студентов. Молодой ученый. 2017; 13(147): 649-651.

2. Ямалетдинова Г.А., Кучумов Д.В. Самоуправление как личностный способ реализации познавательной деятельностью студентов в процессе учебно-тренировочных занятий по КУдО. Теорія и практика фізического виховання. 2011; 3: 232-243.
3. Ямалетдинова Г.А. Физическая культура: учеб. пособие. Екатеринбург: Гуманитарный университет. 2016: 185. 4. Зорин В.И., Анашкин Р.М. Основы КУДО. М. 2004: 169. 5. Кузнецов А.С., Кузнецова З.М. ІІ Съезд членов общественной организации «Российское профессорское собрание». Педагогикопсихологические и медико-биологические проблемы физической культуры и спорта. 2019; 14(4):5-7.DOI:10.14526/2070-4798-2019-14-4-5-7.

6. Войтенко В.П. Здоровъе здоровых. Введение в санологию. К.: Здоровье. 1991: 246

7. Keating X.D., Guan J., Pinero J.C., Bridges D.M. A meta-analysis of college students' physical activity behaviors. Journal of American College Health. 2005; 54: 116126. DOI: $10.3200 / J A C H .54 \cdot 2.116-126$. 8. King A. Public health: Health risks of physical inactivity similar to smoking. Nature Reviews Cardiology. 2012; 9: 492. DOI: 10.1038/nrcardio.2012.115. 9. Pratt M., Norris J., Lobelo F., Roux L., Wang G. The cost of physical inactivity: Moving into the $21^{\text {st }}$ century. British Journal of Sports Medicine. 2012. DOI: 10.1136/bjsports-2012-091810.

\section{Статья поступила в редакиию: 12.11.2020}

Кучумов Дмитрий Вячеславович - преподаватель, 620042, Россия, г. Екатеринбург, проспект Орджоникидзе, дом 23 кв.14, e-mail: ku.dm2015@yandex.ru

Ямалетдинова Галина Александровна - доктор педагогических наук, профессор, Гуманитарный университет, 620042, Россия, г. Екатеринбург, проспект Орджоникидзе, дом 23 кв.14, e-mail:yamalga@mail.ru 